\title{
Factors Associated with Musculoskeletal Injuries While Hiking with a Backpack at Philmont Scout Ranch
}

\author{
Ky B. Stoltzfus, $\mathrm{MD}^{1}$; Alex V. Arvanitakis, $\mathrm{BS}^{2}$; Lauren M. Kennedy, $\mathrm{BS}^{2}$; Kathryn R. McGregor, BS ${ }^{2}$; \\ Bo Zhang, $\mathrm{PhD}^{3}$; Jinxiang $\mathrm{Hu}, \mathrm{PhD}^{3}$ \\ ${ }^{1}$ Department of Internal Medicine University of Kansas Medical Center, Kansas City, Kansas; ${ }^{2}$ University of Kansas Medical Center, Kansas City, \\ Kansas; ${ }^{3}$ Department of Biostats and Data Science, University of Kansas Medical Center, Kansas City, Kansas
}

\begin{abstract}
Introduction-Participants at Philmont Scout Ranch embark on 12-d treks with pre-trek physical conditioning and medical clearance by their primary care physician. In this study, we investigated potential contributing factors to self-reported musculoskeletal injuries during a backpack trek.

Methods - This study was a prospective cohort study that used a 3-part survey administered to participants before, during, and after their trek from June through August 2019. Health history and demographic information were retrieved from each hiker's medical record. A logistic regression model was used to assess factors associated with injuries, and odds ratios and $95 \%$ confidence intervals were reported.

Results-There were 1206 individuals enrolled in this study, and none withdrew from participation. The median age of the participants was $17 \mathrm{y}$ (interquartile range 15-47); 1130 were male, 75 were female, and 1 was of unknown sex. Injuries were reported by $7 \%(n=88)$ of participants while in the backcountry, with injuries occurring in various anatomic locations (knee, ankle, leg, foot, hand, arm). Participants without missing data $(74 \% ; n=897)$ were included in the logistical regression analysis to describe factors significantly associated with injury. Factors significantly associated with injury included greater backpack weight to body weight ratio, body mass index greater than $30 \mathrm{~kg} \cdot \mathrm{m}^{-2}$, and past injuries that required a doctor visit.

Conclusions - Self-reported injuries while hiking at Philmont Scout Ranch are infrequent and do not often require evacuation or advanced medical care. Camp policies to maintain appropriate backpack weight and counseling of obese and previously injured individuals may mitigate injury occurrence.
\end{abstract}

Keywords: mountains, outdoor activity, trek

\section{Introduction}

Hiking, backpacking, and outdoor activities in the mountains have grown in popularity in the United States. The United States Department of Agriculture Forest Service reported in 2011 that $44 \%$ of Americans participate in backcountry activities. ${ }^{1}$ Unfortunately, these activities can be accompanied by a high incidence of injury and illness. ${ }^{2}$ One study investigating injuries among long-distance backpackers showed that $57 \%$ of participants experienced injury or illness. ${ }^{3}$ In another

Corresponding author: Ky B. Stoltzfus, MD, University of Kansas Medical Center, 3901 Rainbow Blvd, MS 1020, Kansas City, KS 66160; e-mail: kstoltzfus@kumc.edu.

Submitted for publication February 2021.

Accepted for publication November 2021. study, $80 \%$ of injuries incurred during outdoor recreational activities were musculoskeletal or soft tissue injuries, and they most often occurred while hiking with a backpack. $^{4}$

Philmont Scout Ranch (PSR), in Cimarron, New Mexico, is operated by the Boy Scouts of America. It contains $507 \mathrm{~km}$ of trail, 35 backcountry camps, and 770 campsites. Approximately 25,000 to 27,000 people participate in treks every summer, with 3500 campers hiking the backcountry every day. These participants include youth as well as adult Scout leaders. There are injuries that occur during hiking and backcountry activities, but this has never been comprehensively assessed at PSR. Each summer, hundreds of participants at Philmont must miss 1 or more days due to musculoskeletal or soft tissue injuries sustained during their trek. 
Table 1. Height-weight requirements to trek

\begin{tabular}{ll}
\hline Height $(\mathrm{cm})$ & Maximum weight $(\mathrm{kg})$ \\
\hline 152 & 75 \\
155 & 78 \\
157 & 81 \\
160 & 83 \\
163 & 86 \\
165 & 89 \\
168 & 91 \\
170 & 94 \\
173 & 97 \\
175 & 100 \\
178 & 103 \\
180 & 106 \\
183 & 109 \\
185 & 112 \\
188 & 115 \\
191 & 118 \\
193 & 121 \\
196 & 125 \\
198 & 128 \\
$\geq 201$ & 134 \\
\hline
\end{tabular}

It remains unclear what factors lead to backpacking injuries and what practices may confer benefit in avoiding injuries. The use of equipment such as trekking poles was previously found to reduce impact on joints and therefore may decrease risk of musculoskeletal injury. ${ }^{5}$ Another study surveyed 771 hikers on the John Muir Trail and found a significant protective relationship between lower backpack weight and the risk of incurring an injury, as well as increased risk of injury with increasing body mass index (BMI). ${ }^{3}$ However, a study of 1283 hikers at the National Outdoor Leadership School failed to elucidate any significant correlation between body weight, backpack weight, age, sex, and musculoskeletal injuries. ${ }^{2}$ Given the lack of consistent evidence for risk factors associated with musculoskeletal injuries while hiking, we sought to investigate the relationship of equipment and individual characteristics to injuries. The aim of this study was to study a large population of youth and adults hiking in the mountains and elucidate the relationship between individual and outdoor factors and the incidence of musculoskeletal and soft tissue injuries at PSR.

\section{Methods}

This study received institutional review board review and approval through the University of Kansas Medical Center in Kansas City, Kansas. This was a prospective cohort study with a 3-part survey administered to hikers participating in 12-d treks at PSR from June through
August 2019. Participants at PSR are screened by their primary care physician for general medical conditions that may preclude safe participation in hiking with a backpack or camp activities, such as uncontrolled asthma, diabetes, hypertension, or serious musculoskeletal injuries. They are also excluded from participating if they exceed height-weight requirements, which are specified by PSR prior to arrival at camp (Table 1).

Participants were voluntarily enrolled while completing their normal pre-trek activities at PSR basecamp. The surveys were completed by participants at the following time periods: pre-trek, completed before hiking (part 1 survey); trail data completed by the participant while hiking (part 2 survey); and post-trek, completed after hiking (part 3 survey). Participants included Scouts (boys and girls) age $14 \mathrm{y}$ and older and leaders age $21 \mathrm{y}$ or older. Each crew spent $1 \mathrm{~d}$ in base camp before departing, $10 \mathrm{~d}$ hiking, and $1 \mathrm{~d}$ in base camp upon return. A document including consent for study participation, information regarding the study's nature, and the intent of encoded disclosure of results was signed by adults age $18 \mathrm{y}$ and over before completion of the first survey. Participants under $18 \mathrm{y}$ of age were required to contact a parent or guardian, and the entirety of the consent form was read out loud by a study coordinator. The name and contact information of the consenting guardian was documented.

Participants initially completed the part 1 survey in base camp before departing on the trek. This included questions about ethnicity, sex, number of training treks lasting 2 or more nights in the past $2 \mathrm{y}$, and previous injuries in the past 2 y requiring a doctor visit. Footwear was defined as hiking boots that cover the ankle, hiking boots or shoes that do not cover the ankle (low cover), running or trail shoes, and other types of footwear. The participants were instructed to weigh their backpacks just before departing to trek, using an American Weigh Scales $\mathrm{H}$ series digital multifunction electronic hanging scale (H-110; Cumming, GA).

The definition of injury for this study was a selfreported acute musculoskeletal or soft tissue injury or fall, joint sprain/strain, overuse/exertion, abrasion, or laceration that was sustained while on a backpack trek. Injuries were further categorized into 2 groups: basic and advanced. A basic injury was one requiring simple first aid in the form of dressing, splint, or wrap provided in the field; requiring the use of a nonsteroidal anti-inflammatory drug, acetaminophen, or other over-thecounter pain medications; or interfering with active participation in activities over the next $12 \mathrm{~h}$. An advanced injury was an injury that included any element of basic injury that also required evacuation to the Philmont infirmary or other medical facility. Hikers 
completed an injury report card themselves for their trek and were instructed to document any injury incurred (part 2a survey). Each injury report card included questions on the body part injured, mechanism of injury, location of injury, kilometers hiked that day, treatment received, and activity during which the injury was sustained. Location of injury was specified as either in camp, which refers to where the participants set up tents and stayed during the evenings, while hiking on the trail, or during backcountry activities. These activities included programs offered by staffed camps in the backcountry, such as mountain biking, horseback riding, or rock climbing. The injury report cards were collected on the day of return after completion of the 12-d trek. Those participants who sustained advanced injuries requiring care at the Philmont infirmary or local hospital were asked advanced injury questions (part $2 b$ survey) by a study coordinator in the infirmary. This included additional questions about treatment location, diagnostic testing, and number of days off the trail for recovery.

The medical history of each participant was gathered from their health and medical record, which was given to the Philmont infirmary staff before departure. Height, weight, medical history, current medications, date of birth, and ZIP code were recorded. Participants were stratified into BMI categories using the following categories outlined by the World Health Organization: underweight: $<19 \mathrm{~kg} \cdot \mathrm{m}^{-2}$; normal weight: $19-24 \mathrm{~kg} \cdot \mathrm{m}^{-2}$; overweight: $25-30 \mathrm{~kg} \cdot \mathrm{m}^{-2}$; and obese: $>30 \mathrm{~kg} \cdot \mathrm{m}^{-2}$. Study data were collected and managed using REDCap electronic data capture tools hosted at the University of Kansas. ${ }^{6}$

Upon returning to base camp after the trek, hikers completed the part 3 survey, which included 2 questions regarding equipment and footwear used on the trail. Participants were given a Philmont infirmary patch for participation.

Descriptive statistics at baseline were provided. Continuous variables were summarized as mean \pm SD and nonnormally distributed variables as median and quartile ranges. Categorical variables were reported as frequency and percentage. Percentage of injured was also reported. Our outcome variable was injury. A logistic regression model was used to determine the predictors of injury. Covariates included were based on the conclusions of a prior study ${ }^{4}$ and the clinical experience of the research team; these included footwear, equipment, backpack weight and bodyweight ratio, BMI, age, sex, race, past injuries that required a visit to a doctor, and past backpack trips. Odds ratios, 95\% confidence intervals (CIs), and $P$ values were reported. $P$ values of $<0.05$ were considered significant. All statistical analyses were conducted in R ( $\mathrm{R}$ core team, 2019). The logistical regression analysis was as follows:

$$
\begin{aligned}
& \text { Logit }(Y)=\beta_{0}+\beta_{1} \times \text { Footwear }+\beta_{2} \times \text { Equipment } \\
& +\beta_{3} \times \text { Backpackweight } / B W+\beta_{4} \times B M I+\beta_{5} \times \text { Age } \\
& +\beta_{6} \times \text { Sex }+\beta_{7} \times \text { Race }+\beta_{8} \\
& \times \text { PastInjuryRequiringDoctorVisit }+\beta_{9} \\
& \times \text { PastBackPacking }
\end{aligned}
$$

\section{Results}

We enrolled 1206 participants in the study, and none withdrew from participation. Seven percent of participants $(n=88)$ reported an injury while in the backcountry. Participant demographics, self-reported injury history, and equipment used are listed in Table 2. The data presented in Table 2 reflect the overall study population, including those with missing data. The sample of participants includes a disproportionate number of white and male hikers. The BMI of the majority of participants was classified as normal or underweight (55\%), but there were still a large number of overweight $(30 \%)$ and obese $(15 \%)$ individuals, which is reflective of the population in the United States in general. ${ }^{7}$ The BMI percentiles were calculated using 1200 of the 1206 participants because BMI data were missing for 6 participants. Most participants $(76 \%)$ wore hiking boots that covered the ankles. Trekking poles were an often-used piece of additional equipment (56\%), and other aides were infrequently used (12\% for all other combined categories). Questions about footwear and equipment used were asked in the part 3 survey (post-trek) and are reported in Table 3. In the past $2 \mathrm{y}, 28 \%(\mathrm{n}=334)$ of participants reported an injury that required prior treatment by a physician. We were unable to summarize kilometers hiked because $>25 \%$ of participants had missing data on their survey cards for this item. Consequently, we exclude kilometers hiked from Table 2.

We describe anatomic location and type of self-reported injury in Table 3. Injuries were evenly distributed to different anatomic locations and type. Most injuries occurred while the participant was hiking, with much fewer occurring while at the campsite or doing other activities. Lacerations and abrasions accounted for 59 of the 130 basic injuries.

Treatments received varied both with basic and advanced injuries. Only 2 participants were injured severely enough to require evaluation and treatment at a local hospital. Most participants were able to return to hiking activities after advanced injuries. 
Table 2. Participant demographics, history, and equipment (part 1 survey)

\begin{tabular}{|c|c|c|c|}
\hline & & Total & Injured $^{a}$ \\
\hline & & $n=1206$ & $n=88(7 \%)$ \\
\hline Age $(y)$ & Median (Q1-Q3) & $17(15-47)$ & $19(15-48)$ \\
\hline Pack weight $(\mathrm{kg})$ & Median (Q1-Q3) & $20.5(18.6-22.7)$ & $21.7(19.0-23.6)$ \\
\hline Pack weight/bodyweight & Median (Q1-Q3) & $0.13(0.11-0.15)$ & $0.13(0.11-0.15)$ \\
\hline \multirow[t]{3}{*}{ Sex } & Male & 1130 & $77(7)$ \\
\hline & Female & 75 & $11(15)$ \\
\hline & Unknown & 1 & $0(0)$ \\
\hline \multirow[t]{8}{*}{ Race } & White & 1131 & $81(7)$ \\
\hline & Hispanic & 52 & $6(12)$ \\
\hline & Asian & 40 & $5(13)$ \\
\hline & Alaskan Native & 14 & $4(29)$ \\
\hline & Black & 10 & $1(10)$ \\
\hline & Native American & 10 & $4(40)$ \\
\hline & Other & 8 & $0(0)$ \\
\hline & Prefer to not answer & 7 & $0(0)$ \\
\hline \multirow[t]{3}{*}{ Ethnicity } & White & 1079 & $74(7)$ \\
\hline & Non-White & 120 & $14(12)$ \\
\hline & NA & 7 & $0(0)$ \\
\hline \multirow[t]{4}{*}{ BMI $\left(\mathrm{kg} \cdot \mathrm{m}^{-2}\right)$} & Underweight & 129 & $8(6)$ \\
\hline & Normal & 534 & $37(7)$ \\
\hline & Overweight & 358 & $25(7)$ \\
\hline & Obese & 179 & $17(10)$ \\
\hline \multirow[t]{5}{*}{ Footwear $^{b}$} & Hiking boots that cover the ankle & 840 & $74(9)$ \\
\hline & Low cover & 80 & $12(15)$ \\
\hline & Running or trail shoe & 39 & $0(0)$ \\
\hline & Other footwear & 2 & $0(0)$ \\
\hline & No answer & 245 & $2(1)$ \\
\hline \multirow[t]{5}{*}{ Equipment $^{b}$} & Trekking poles & 616 & $64(10)$ \\
\hline & Leg sleeves & 65 & $6(9)$ \\
\hline & Walking stick & 32 & $3(9)$ \\
\hline & Other & 31 & $4(13)$ \\
\hline & None & 294 & $18(6)$ \\
\hline \multirow[t]{4}{*}{ Past injuries requiring doctor visit } & $1-2$ times & 279 & $26(9)$ \\
\hline & $3-5$ times & 42 & 7 (17) \\
\hline & $>5$ times & 13 & $0(0)$ \\
\hline & None & 872 & $55(6)$ \\
\hline
\end{tabular}

${ }^{a}$ Injured $\%=$ Injured $/$ Total $* 100 \%$.

${ }^{b}$ Part 3 survey data.

We removed 309 participants from the analysis owing to missing data. The number of participants included in the logistic regression was 897 . There was no statistically significant difference in demographics compared to the full cohort. The logistic regression analysis results shown in Table 4 describes factors that are significantly associated with injuries. Backpack weight to body weight ratio (odds ratio $=1.1,95 \% \mathrm{CI}$ 1.01-1.20, $P=0.02$ ) has a significant association with injury. Within the range of the subjects' pack weight to body weight ratio of $5 \%$ to $33 \%$, every $1 \%$ increase in ratio results in an $11 \%$ increase in the odds of injury. Participants with a BMI in the obese category had a significantly increased risk of injury of 2.4 times the odds of injury (95\% CI 1.08-5.28, $P=0.03$ ) compared to normal and underweight individuals. Participants with a BMI in the overweight category did not have a significant increase in associated injury compared to normal and underweight individuals. Those who had a self-reported past injury that required a physician visit prior to their hiking trek had 1.7 times the odds of injury $(95 \%$ CI 1.04-2.81, $P=0.03$ ) compared to individuals with no history of injury. Other factors within our model of equipment used age, sex, race, or prior hiking experience and did not show protective or harmful association with injury. 
Table 3. Reported injuries while hiking (part 2 of survey)

\begin{tabular}{|c|c|c|}
\hline & $\begin{array}{l}\text { Basic injury } \\
(n=130)^{a, b}\end{array}$ & $\begin{array}{l}\text { Advanced } \\
\text { injury } \\
(n=10)^{a, c}\end{array}$ \\
\hline \multicolumn{3}{|l|}{ Part of body injured } \\
\hline Leg & 38 & 0 \\
\hline Foot & 30 & 1 \\
\hline Knee & 29 & 2 \\
\hline Ankle & 29 & 4 \\
\hline Hand & 18 & 0 \\
\hline Other & 17 & 3 \\
\hline Arm & 9 & 0 \\
\hline Back & 8 & 1 \\
\hline \multicolumn{3}{|l|}{ Type of injury } \\
\hline Joint sprain & 39 & 5 \\
\hline Overuse/Exertion & 37 & 0 \\
\hline Laceration & 28 & 0 \\
\hline Abrasion & 31 & 0 \\
\hline Fall & 21 & 5 \\
\hline \multicolumn{3}{|l|}{ Injury location } \\
\hline While hiking & 110 & 1 \\
\hline Camp & 21 & 8 \\
\hline Backcountry activity & 21 & 1 \\
\hline $\begin{array}{l}\text { Average reported } \\
\text { kilometers hiked }^{d}\end{array}$ & 11.4 & 11.3 \\
\hline \multicolumn{3}{|l|}{ Treatment received } \\
\hline Wrap/Bandage & 75 & 4 \\
\hline $\begin{array}{l}\text { NSAID, acetaminophen, } \\
\text { or other OTC pain } \\
\text { medications }\end{array}$ & 63 & 10 \\
\hline Rest for more than $12 \mathrm{~h}$ & 14 & 5 \\
\hline Ice & 9 & 5 \\
\hline Splint & 0 & 4 \\
\hline Stitches & 0 & 0 \\
\hline \multicolumn{3}{|l|}{$\begin{array}{l}\text { Advanced injury } \\
\text { treatment location }\end{array}$} \\
\hline Infirmary & & 8 \\
\hline Hospital & & 2 \\
\hline Outside clinic & & 0 \\
\hline $\begin{array}{l}\text { Average number of days } \\
\text { off trail }\end{array}$ & & 2 \\
\hline
\end{tabular}

NSAID, nonsteroidal anti-inflammatory drug; OTC, over the counter.

${ }^{a}$ Twenty-two participants had multiple injuries.

${ }^{b}$ Part 2a of survey.

${ }^{c}$ Part $2 \mathrm{~b}$ of survey.

${ }^{d}$ Kilometers hiked is only reported in this table; it is not reported elsewhere owing to missing data.

\section{Discussion}

In our study of youth hikers and their adult leaders, we found an overall rate of self-reported injury of $7 \%$. This was expected, given our clinical experience with these participants, and is similar to injury rates of military soldiers undergoing rigorous outdoor training (when blisters are excluded as a type of injury). ${ }^{8}$ Many injuries were of a basic nature that could be successfully managed in the backcountry setting without the expertise of a medical professional. Lacerations and abrasions accounted for nearly half of the basic injuries and none of the advanced injuries, offering reassurance that they can be managed with first aid skills of the participants or leaders.

The basic first aid skills and training of Scouts and their leaders may be an effective skillset to mitigate the need for advanced medical care; this is supported indirectly in a prior study showing that individuals with greater medical knowledge and skills effectively avoided injury more often while hiking. ${ }^{9}$ The requirement for each group of participants to have at least 2 individuals trained in wilderness first aid is outlined in the health advisory forms provided prior to hiking. Only a small number of participants had injuries severe enough to require evacuation to the medical infirmary or local hospital.

Although injuries are likely to happen with any physical activity or sport, it is helpful to understand which individuals are most likely to be injured. Individuals carrying heavier backpacks are more likely to be injured. Our findings are congruent with a previous study demonstrating that carrying a heavier backpack leads to greater incidence of parathesias ${ }^{10}$; however, we studied a broader spectrum of injuries, which adds to that knowledge base. The strong relationship we found reinforces the need to have camp policies in place for allowable backpack weight so that safe backpack weight to body weight ratios are not exceeded. This study was not designed to determine a cutoff backpack weight to reduce injuries; however, current PSR guidance of not exceeding a 25 to $30 \%$ backpack weight to bodyweight ratio appears to be prudent given our findings.

Individuals who have a previous injury are more susceptible to either reinjury or new injury. These individuals may benefit from additional pre-trail counseling about injury prevention. In some instances, avoiding hiking after serious or repetitive injuries may also be advisable.

Many participants at PSR were overweight or obese. Hiking is an excellent form of physical activity and will likely convey some health benefits. However, individuals with a BMI $>30 \mathrm{~kg} \cdot \mathrm{m}^{-2}$ have greater association with injury. This is consistent with prior evidence of the strong association between musculoskeletal pain or injury in obese adolescents and adults. ${ }^{11,12}$ These individuals may also benefit from pre-trek counseling of additional weight loss many months in advance for injury prevention. PSR has height-weight guidelines that are closely enforced but do not preclude all obese 
Table 4. Logistic regression analysis

\begin{tabular}{llll}
\hline & Estimate & OR $(95 \%$ CI $)$ & $P$ \\
\hline Age (y) & 0.01 & $1.01(0.99-1.03)$ & 0.31 \\
Male sex & -0.64 & $0.53(0.25-1.21)$ & 0.10 \\
Race, non-white $^{a}$ & 0.59 & $1.81(0.91-3.39)$ & 0.07 \\
Footwear $^{b}$ & 0.06 & $1.07(0.53-2.38)$ & 0.87 \\
Equipment $^{c}$ & 0.43 & $1.54(0.86-2.82)$ & 0.15 \\
Packweight/Bodyweight $_{\text {BMI }}{ }$ & 0.1 & $1.11(1.01-1.20)$ & $0.02^{d}$ \\
$\quad$ Underweight/Normal $_{\text {Overweight }}$ & Reference & & \\
$\quad$ Obese & 0.31 & $1.36(0.69-2.65)$ & 0.37 \\
Past injuries requiring doctor visit & 0.87 & $2.39(1.08-5.28)$ & $0.03^{d}$ \\
Past backpacking trip & & $1.72(1.04-2.81)$ & $0.03^{d}$ \\
\hline
\end{tabular}

${ }^{a}$ Race $=0$ if white and 1 if non-white.

${ }^{b}$ Footwear $=1$ if hiking boot that covers ankle and 0 otherwise.

${ }^{c}$ Equipment $=1$ if yes and 0 if no.

${ }^{d}$ Statistically significant.

${ }^{e} \mathrm{BMI}=0$ if underweight and normal category, $\mathrm{BMI}=1$ if overweight category, $\mathrm{BMI}=2$ if obese category.

${ }^{f}$ Past injuries requiring doctor visit $=0$ if no and 1 if yes.

${ }^{g}$ Past backpacking trip $=0$ if no and 1 if yes.

individuals from hiking and may not be enough to prevent injuries in obese individuals.

Use of different types of footwear and hiking equipment, such as trekking poles, did not have a significant impact on the incidence of reported injuries. Consequently, we cannot provide a recommendation to hikers at PSR about the optimal equipment to use to prevent injuries. Other demographic factors also had no impact on reported injuries and should have no bearing on a participant's ability to hike safely.

\section{LIMITATIONS}

Participants in this study were predominantly white, male, and younger, which may not reflect the general population of hikers with backpacks. We were limited by the overall make-up of participants at PSR.

We relied on participants to complete self-reported data collection while hiking. It was not feasible for us to collect researcher-recorded injury data on a large population spread out over a large geographic area that is mostly inaccessible by vehicle. The injury report cards they completed had some missing data, and we asked participants not to add data later if an entry was incomplete to avoid recall bias. With self-recorded data, it is possible that a participant may not have completed an entry for a particular injury. We chose to eliminate participants with missing data from the logistic regression analysis.

\section{Conclusions}

Hiking with a backpack is generally a safe activity, and musculoskeletal injury is an infrequent complication. Injuries associated with backpacking can often be treated in the backcountry setting, allowing hikers to continue with their trek. Injuries were found to be significantly associated with greater backpack weight to body weight ratio, BMI in the obese category, and history of injury prior to the hiking trek. Additional camp policies to address risk for the most injury-susceptible individuals may be needed to mitigate these factors.

Acknowledgments: The authors thank the participants who volunteered for this study. We thank Nate Lay for his assistance with study logistics.

Author Contributions: Study concept and design (KS, AA, CM); study execution (AA, CM, LK); drafting of the manuscript, review, and approval of final manuscript (all authors).

Financial/Material Support: This study received funding from Philmont Scout Ranch for summer research internship support (AA, CM, LK). The University of Kansas Medical Center provided funding for statistical support and analysis. PSR provided patches for participation, which have no monetary value.

Disclosures: None.

\section{References}

1. Cordell HK, Betz CJ, Mou SH, Gormanson DD. Outdoor recreation in the northern United States. Newtown Square, PA: USDA Forest Service. Available at: https://www.fs.fed.us/nrs/pubs/gtr/gtr_ nrs 100.pdf; 2012. Accessed February 1, 2021. 
2. Hamonko MT, McIntosh SE, Schimelpfenig T, Leemon D. Injuries related to hiking with a pack during National Outdoor Leadership School courses: a risk factor analysis. Wilderness Environ Med. 2011;22(1):2-6.

3. Spano SJ, Hile AG, Jain R, Stalcup PR. The epidemiology and medical morbidity of long-distance backpackers on the John Muir trail in the Sierra Nevada. Wilderness Environ Med. 2018;29(2):203-10.

4. Leemon D, Schimelpfenig T. Wilderness injury, illness, and evacuation: National Outdoor Leadership School's incident profiles, 1999-2002. Wilderness Environ Med. 2003;14(3):174-82.

5. Bohne M, Abendroth-Smith J. Effects of hiking downhill using trekking poles while carrying external loads. Med Sci Sports Exerc. 2007;39(1):177-83.

6. Harris PA, Taylor R, Thielke R, Payne J, Gonzalez N, Conde JG. Research electronic data capture (REDCap)-a metadata-driven methodology and workflow process for providing translational research informatics support. J Biomed Inform. 2009;42(2):377-81.

7. Fryar CD, Kruszon-Moran D, Gu Q, Ogden CL. Mean body weight, height, waist circumference, and body mass index among adults:
United States,1999-2000 through 2015-2016. National health statistics reports; no 122. Hyattsville, MD: National Center for Health Statistics; 2018.

8. Knapik J, Farina E, Ramirez C, Pasiakos S, McClung J, Lieberman H. Medical encounters during the United States Army Special Forces Assessment and Selection course. Mil Med. 2019;184(7-8):e337-43.

9. Yue MD, Spivey DW, Gingold DB, Sward DG. The effect of wilderness and medical training on injury and altitude preparedness among backcountry hikers in Rocky Mountain National Park. World J Emerg Med. 2018;9(3):172-7.

10. Anderson Jr LS, Rebholz CM, White LF, Mitchell P, Curcio 3rd EP, Feldman JA, et al. The impact of footwear and packweight on injury and illness among long-distance hikers. Wilderness Environ Med. 2009;20(3):250-6.

11. Deere KC, Clinch J, Holliday K, McBeth J, Crawley EM, Sayers A, et al. Obesity is a risk factor for musculoskeletal pain in adolescents: findings from a population-based cohort. Pain. 2012;153(9):1932-8.

12. Amoako AO, Nassim A, Keller C. Body mass index as a predictor of injuries in athletics. Curr Sports Med Rep. 2017;16(4):256-62. 